\title{
Inter-relationship between microsatellite instability, thymidylate synthase expression, and p53 status in colorectal cancer: implications for chemoresistance Sanjay Popat*, Richard Wort and Richard S Houlston
}

Address: Section of Cancer Genetics, Institute of Cancer Research, Sutton, Surrey, SM2 5NG, UK

Email: Sanjay Popat* - sanjay.popat@icr.ac.uk; Richard Wort - richard.wort@icr.ac.uk; Richard S Houlston - richard.houlston@icr.ac.uk

* Corresponding author

Published: 05 June 2006

BMC Cancer 2006, 6:150 doi:10.1186/147|-2407-6-150

This article is available from: http://www.biomedcentral.com/I47/-2407/6/150

(C) 2006 Popat et al; licensee BioMed Central Ltd.

This is an Open Access article distributed under the terms of the Creative Commons Attribution License (http://creativecommons.org/licenses/by/2.0), which permits unrestricted use, distribution, and reproduction in any medium, provided the original work is properly cited.

\begin{abstract}
Background: Studies indicate that thymidylate synthase (TS) expression, p53 and mismatch repair status have potential to influence colorectal cancer (CRC) outcome. There is, however, little data on the inter-relationship between these three markers. We sought to investigate whether relationships exist between these markers that might contribute to CRC phenotypes.

Methods: Four hundred and forty-one stage I-III CRCs were investigated. p53 status and TS expression were assessed by standard immunohistochemistry methods. Mismatch repair status was determined by assessment of microsatellite instability (MSI) using radiolabelled microsatellite genotyping.

Results: 244 tumours (55\%) over-expressed p53, and 259 (58\%) expressed high TS levels. 65 tumours (15\%) had MSI. A significant relationship between p53 over-expression and high TS expression was observed $(p=0.0 \mathrm{I})$. This was independent of MSI status. A highly significant inverse relationship between MSI and $p 53$ status was observed $(p=0.00 \mathrm{I})$. No relationship was seen between MSI status and TS expression $(\mathrm{p}=0.59)$.

Conclusion: Relationships exist between p53 status and TS expression, and MSI and p53 status. These inter-relationships may contribute to the clinical phenotype of CRCs associated with each of the molecular markers. High TS expression is unlikely to account for the clinical behaviour of CRCs with MSI.
\end{abstract}

\section{Background}

Colorectal cancer (CRC) is one of the commonest malignancies of developed countries [1], with approximately 19,000 and 160,000 new cases in the UK and US, respectively, each year, and around 500,000 new cases worldwide $[2,3]$. CRC tumourigenesis is a multi-step phenomenon, typified by a series of genomic events that parallel development of invasive malignancy from normal epithelium through formation of pre-malignant adenomas [4].
Whilst most ( $85 \%)$ CRCs develop through the chromosomal instability pathway, in which adenoma formation is typified by loss of APC function, and development of invasive malignancy by TP53 mutation [4], a smaller number $(\sim 15 \%)$ develop as a consequence of mismatch repair (MMR) deficiency. These tumours are characterised by high frequency microsatellite instability (MSI), proximal colonic distribution, poor differentiation, mucinous appearance, and lymphocytic infiltration [5]. Addition- 
ally, these tumours tend to retain the native diploid state [5]. By contrast, chromosomally unstable tumours tend to be aneuploid and have no site predilection [6].

Several studies have demonstrated that tumour molecular phenotype is a determinant of CRC prognosis [7-9]. Although many markers of prognosis have been investigated in recent years, the most promising to date are mismatch repair status, thymidylate synthase (TS) expression level, and p53 status.

Tumours developing through the mismatch repair pathway are characterised by loss of mismatch repair gene function (primarily $h M L H 1$ ), through either mutation or more commonly, epigenetic change [5]. This results in somatic hypermutability most pronounced at short tandem repeat sequences such as microsatellites, termed microsatellite instability (MSI), readily detectable by the presence/absence of novel alleles or the shortening of at least 2-3 repeat units by electrophoresis. Several studies of clinical datasets have indicated that CRCs with MSI are associated with improved survival [10]. However, in vitro data has indicated that these tumours are paradoxically characterised by $5 \mathrm{FU}$ chemoresistance $[11,12]$. Although the mechanism for these observations remain unclear, the notion that fluoropyrimidine sensitivity might be modulated through either TS expression or p53 mutation is plausible [13]. Thymidylate synthase (TS) is a major protein involved in CRC development and outcome. As well as providing the sole intracellular source of thymidine for DNA synthesis [14], TS is also a target for a number of drugs used for CRC treatment, including 5-fluorouracil (5FU), whose mechanism of action is primarily mediated through competitive TS inhibition. Thymidylate synthase expression has been shown to be a key determinant of 5FU resistance in vitro $[14,15]$ and several patient series have confirmed poorer outcomes in those with tumours expressing high TS levels [16]. Mutation in the tumour suppressor TP53 has also been associated with chemoresistance and poorer survival in CRC $[17,18]$. TP53 maps to chromosome $17 \mathrm{p} 13.1$ [19] and is one of the commonest genes mutated in CRC, encoding a transcription factor (p53) critically involved in control of cell cycle, apoptosis, and carcinogenesis [20-25].

Whilst each of these markers impact on CRC prognosis, the inter-relationship between each has been the subject of few studies. Hence, the contribution to the clinical behaviour of CRCs associated with either p53, TS or mismatch repair status of any such inter-relationship is unclear. Here we report analysis of the largest series of early stage CRC assessed for these three clinically relevant molecular co-variates.

\section{Methods \\ Patients}

Four hundred and forty-one paired paraffin-embedded formalin fixed tissue blocks (one tumour tissue and one normal tissue) from patients with stage I-III CRC collected at the time of potentially curative surgery were assessed. The study was conducted in accordance with the tenets of the Declaration of Helsinki.

Fifteen-micron sections of formalin-fixed paraffin embedded tumours were cut onto double-sided clear adhesive tape on glass slides. Regions of $\geq 70 \%$ tumour were microdissected after light staining with toluidine blue. Tenmicron whole sections of normal mucosa from a separate paired block of normal colorectal mucosa from each patient were provided as a source of germline DNA extraction. DNA was extracted using standard commercially available methods (Qiagen, West Sussex, UK) and genotyping was performed at the highly sensitive and specific mononucleotide microsatellite locus BAT26 [26,27]. In cases where no paired normal tissue was available, tumour DNA was genotyped alone. Target DNA sequences were amplified using ${ }^{32} \mathrm{P}$ end-labelled primers. Mismatch repair status was assigned as MSI or microsatellite stable (MSS) by presence or absence of novel alleles or the shortening of at least 2-3 repeat units at autoradiography. Genotyping was performed at least twice per sample. Only tumours with unambiguous genotypes were assigned MSI status.

\section{p53 and TS evaluation}

Three micron sections from a representative part of the primary tumour were cut onto silane coated glass slides and assessed for TS and p53 expression by the avidinbiotin complex immunohistochemical technique (Vectastain Elite ABC kit, Vector Laboratories Inc, Burlingame, CA, USA) [28]. Negative and positive control slides were included in each staining run. Primary antibody was replaced with phosphate buffered saline, $\mathrm{pH}$ 7.6/0.1\% (v/ v) Tween solution for negative controls, and tumour sections known to stain heavily for target antigens were used for positive controls.

Tumour sections were deparaffinized in Histoclear (National Diagnostics, Hull, UK) and hydrated in decreasing concentrations of ethanol. Endogenous peroxidase activity was quenched with $5 \%$ hydrogen peroxide in methanol for 20 minutes. Antigen retrieval was required for p53 only and was by a microwave oven-based method. Specifically, sections were incubated in boiling $10 \mathrm{mmol} /$ $\mathrm{L}$ citric acid buffer ( $\mathrm{pH}$ 6.0) for 10 minutes and then cooled in running water. For both TS and p53, non-specific background staining was blocked with $20 \%$ goat serum for 20 minutes. Sections were then incubated with appropriate primary antibodies at a 1:100 dilution, in a 
humidified chamber at room temperature for 60 minutes, using either a validated rabbit polyclonal antibody to recombinant human TS [29], or an anti-p53 mouse monoclonal (clone DO-7, Dako Corp, Denmark). After rinsing, a biotinylated anti-rabbit secondary antibody was applied for 30 minutes followed by further washing, and avidin-biotin-peroxidase complexes (Vectastain Elite ABC kit; Vector Laboratories Inc, Burlingame, CA, USA). Immunostaining was developed by applying freshly prepared $0.05 \%$ 3, 3'-diaminobenzidine tetrahydrochloride (Vectastain Elite ABC kit, Vector laboratories). Sections were counterstained in Mayer's Haematoxylin (Sigma Chemical Co., St Louis, MO, USA), dehydrated in a series of ethanols, cleared in Histoclear (National Diagnostics, Hull, UK) and mounted with glass coverslips using DePeX (BDH, Poole, UK).

\section{Immunohistochemistry evaluation}

All slides were randomly allocated for independent assessment by two observers (RSH and SP), blinded to marker status. TS expression was assessed using the commonest reported method; a semiquantative grading of tumour tissue for chromagen intensity from 0 to 3 , with the highest tumour staining detected as the reference for classification. Grades 0 and 1 , representing none and minimal staining respectively, were defined as the "low" expression group, whereas grades 2 and 3 were defined as the "high" expression group. p53 immunoreactivity was dichotomised into positive or negative based on staining of malignant nuclei, with a threshold of $10 \%$.

Level of scoring agreement between the two observers was recorded. In cases of disagreement, marker status was discussed and determined by consensus.

\section{Statistical analysis}

All statistical manipulations were preformed using STATA (Version 7, Stata Corp. TX77840, USA). Relationships between TS, p53 expression, and MSI status were assessed with Fisher's exact test, stratified by relevant marker.

\section{Results}

Tumour phenotypes

Genotype data was available from all 441 specimens. Sixty-five (15\%) tumours demonstrated MSI, whereas 376 had MSS. Figure 1 shows representative tumour genotypes, with two examples of MSI.

One quarter of the tumours stained for TS with grade 3 $(101,23 \%)$ or grade $0(15,3 \%)$ levels of chromagen intensity, whilst three-quarters stained with either grade 1 $(167,38 \%)$ or grade $2(158,36 \%)$ intensity. When dichotomised into high and low levels of TS expression, just over half of the samples expressed high TS levels $(259,59 \%)$, with the remainder having low-level expression (182,

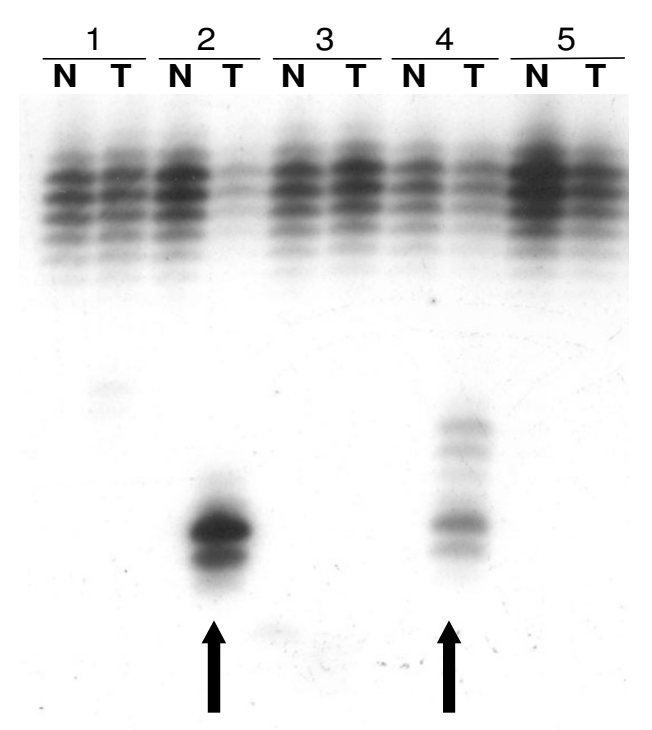

Figure I

Representative examples of microsatellite instability (MSI). Somatic ( $\mathrm{T}$ lanes) and paired germline ( $\mathrm{N}$ lanes) genotypes at the microsatellite marker BAT26 detected by autoradiography in 5 normal/normal pairs are shown. New somatic alleles (lanes T) (tumours 2 and 4) compared to germline genotypes (lanes $\mathrm{N}$ ), as indicated by the arrows, are indicative of MSI.

$41 \%)$. Just over half demonstrated p53 over-expression $(244,55 \%)$, with the remainder showing neither overexpression nor staining $(197,45 \%)$. Figures 2 and 3 show representative sections stained for TS and p53, respectively, demonstrating levels of chromagen intensity required to allocate expression status.

\section{Inter-relationship between p53, TS, and mismatch repair status}

A significant association between $\mathrm{p} 53$ status and TS chromagen intensity was observed ( $p=0.01$ ). This was maintained when dichotomising TS expression into high and low groups. Specifically, tumours with p53 over-expression were significantly associated with high TS levels $(\mathrm{p}=$ 0.005 , Table 1 ). When stratified by MSI status, a relationship between p53 status and TS level was again observed ( $\mathrm{p}=0.005$ ), with tumours over-expressing $\mathrm{p} 53$ (p53 positive) tending to express high TS levels. This relationship was maintained in both subsets of tumours with MSS ( $\mathrm{p}=$ 0.01 , Table 1$)$, and MSI ( $\mathrm{p}=0.30$, Table 1$)$. Although this relationship did not reach formal statistical significance in MSI tumours, this was likely due to the small numbers of tumours assessed, since an over-representation of p53 positive tumours with high TS levels was again observed.

As expected, a highly significant inverse relationship between mismatch repair status and p53 status was 

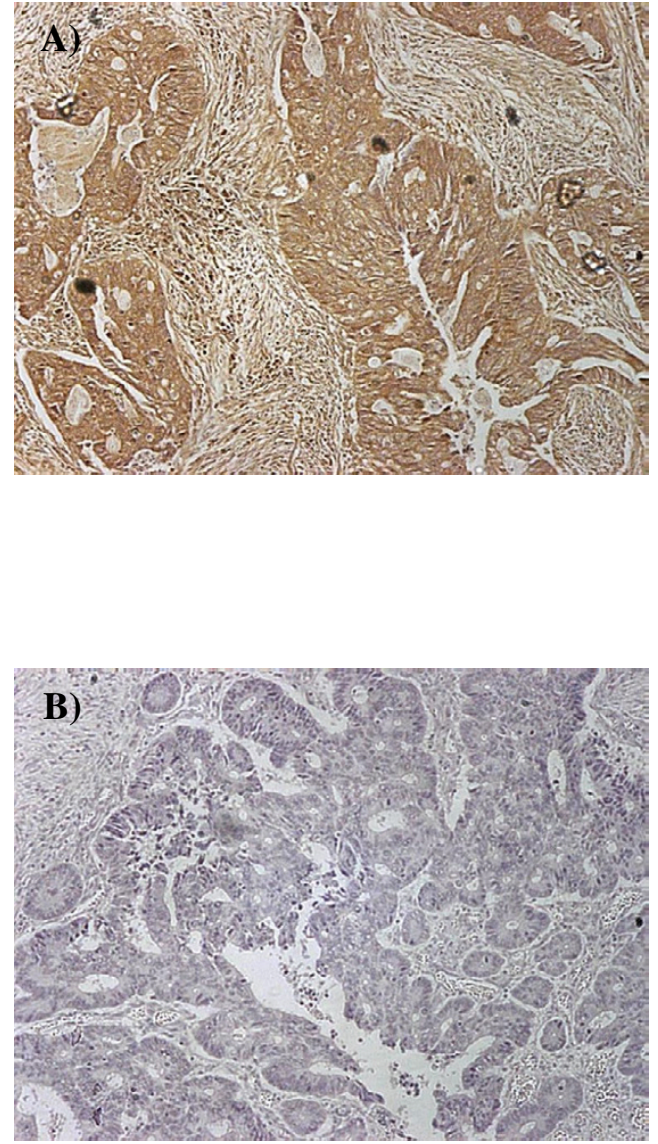

\section{Figure 2}

Immunohistochemical analysis of tumours for thymidylate synthase (TS) showing (a) high level, and (b) low level TS expression.

observed; MSI tumours tending to be p53 negative ( $\mathrm{p}=$ 0.001 , Table 2). This was maintained and not influenced by TS status (Table 2 ).

No relationship was observed between mismatch repair status and TS level ( $p=0.59$, Table 3$)$ and p53 status did not impact on these findings (Table 3 ).

In order to exclude any bias that may have resulted from erroneous classification, we reassessed p53 status using thresholds of $5 \%$ and $15 \%$. This resulted in no reclassification, and therefore no change in associations. Our results were further re-analysed using the Pearson $\chi^{2}$ test. All significant and non-significant associations were maintained. Our results have therefore been reported using the Fisher test, which gives the exact p value, rather than the asymptotic value calculated by the $\chi^{2}$ test.
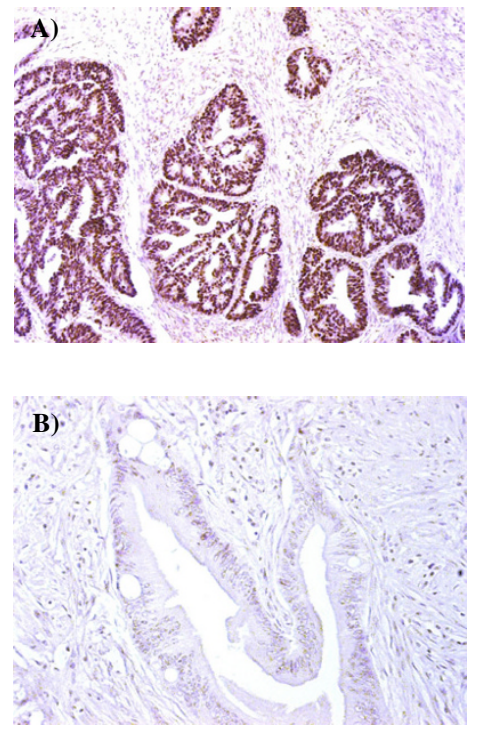

\section{Figure 3}

Immunohistochemical analysis of tumours for p53 (a) p53 over-expression, (b) no p53 over-expression.

\section{Discussion}

We have investigated the relationship between MSI, TS and p53 status using standard genotyping and immunohistochemical methods in early stage CRC. Although only loosely correlating with TP53 mutation, p53 nuclear overexpression detected by IHC has been found to be a marker of worse prognosis in many previously published analyses of CRC datasets [21,30,31]. Our results indicate a highly significant association between p53 status and TS expression, with CRCs expressing high TS levels more likely to over-express p53, regardless of MSI status.

In normal cells, regulation of both TS and p53 are independently tightly controlled. In addition to it's role in enzyme catalysis, TS also functions as a RNA binding protein $[32,33]$, regulating it's own expression by a negative autoregulatory mechanism $[33,34]$, as well as binding to it's own RNA, to form TS-ribonucleoprotein complexes with several RNA species including $c-m y c$ and TP53 [35]. Although in vitro data indicates that p53 and TS have the ability to regulate each-other in non-malignant cells $[32,33,36]$, evidence for a relationship in CRC has been conflicting, with some studies reporting that TS negatively regulates p53 expression [37], whilst others have shown no such relationship $[38,39]$. In addition, the potential for wild-type p53 to regulate TS expression has also been demonstrated using a luciferase-based system, which showed that p53 expression can inhibit TYMS promoter activity [40]. These results are, however, based on in vitro analysis, and no studies have characterised the role of 
Table I: Relationship between TS and p53 expression, stratified by microsatellite instability status.

\begin{tabular}{|c|c|c|c|c|}
\hline \multirow[t]{2}{*}{ MSI status } & \multirow[t]{2}{*}{ p53 status } & \multicolumn{2}{|c|}{ TS status } & \multirow[b]{2}{*}{ Total } \\
\hline & & Low & High & \\
\hline \multirow[t]{3}{*}{ All tumours } & + & 86 & 158 & 244 \\
\hline & - & 96 & 101 & 197 \\
\hline & Total & 182 & 259 & $441^{*}$ \\
\hline \multirow[t]{3}{*}{ MSI tumours } & + & 8 & 15 & 23 \\
\hline & - & 21 & 21 & 42 \\
\hline & Total & 29 & 36 & $65 * *$ \\
\hline \multirow[t]{3}{*}{ MSS tumours } & + & 78 & 143 & 221 \\
\hline & - & 75 & 80 & 155 \\
\hline & Total & 153 & 80 & $376 * * *$ \\
\hline
\end{tabular}

${ }^{*} \mathrm{p}=0.005 ; *_{\mathrm{p}}=0.30 ;{ }^{* * *} \mathrm{p}=0.0 \mathrm{I} ; \mathrm{MSS}$, microsatellite stable; MSI, microsatellite instability; TS, thymidylate synthase

mutant p53 or whether aberrant mismatch repair impacts on the relationship. Our results suggest a relationship between TP53 status and TS expression implying that the poor prognosis and chemoresistance observed in studies of CRC patients with either high TS expression or TP53 mutation/p53 over-expression, may have been impacted on by either co-variate.

A number of potential mechanisms may account for our findings. TP53 mutation is associated with loss of transcriptional activity control resulting in up- or down-regulation of downstream p53 effectors. Thus, inactive p53 might disinhibit an inhibitory role of p53 on TS expression. Alternatively, according to the gain-of-function paradigm [41], mutant p53 might acquire novel activities that promote cell growth and survival [42], perhaps through enhanced TS expression. An example of the latter case is the 273 Arg-His mutation, which has strong transactivating activity [43]. Although the role of this specific mutation in regulating TS expression is unknown, it is feasible that specific p53 mutations retain transcriptional regulatory activity, which may be partially responsible for control of transcriptional activity of proteins such as TS. Supporting this, Lenz et al. investigated the relationship

Table 2: Relationship between p53 expression and microsatellite instability status, stratified by TS expression.

\begin{tabular}{|c|c|c|c|c|}
\hline \multirow[t]{2}{*}{ TS status } & \multirow[t]{2}{*}{ p53 status } & \multicolumn{2}{|c|}{ MSI status } & \multirow[b]{2}{*}{ Total } \\
\hline & & MSS & MSI & \\
\hline \multirow[t]{3}{*}{ All tumours } & + & 221 & 23 & 244 \\
\hline & - & 155 & 42 & 197 \\
\hline & Total & 376 & 65 & $44 I^{*}$ \\
\hline \multirow[t]{3}{*}{ TS low level tumours } & + & 78 & 8 & 86 \\
\hline & - & 75 & 21 & 96 \\
\hline & Total & 153 & 29 & $182^{* *}$ \\
\hline \multirow[t]{3}{*}{ TS high level tumours } & + & 143 & 15 & 158 \\
\hline & - & 80 & 21 & 101 \\
\hline & Total & 223 & 36 & $259 * * *$ \\
\hline
\end{tabular}

${ }^{*} \mathrm{p}=0.001 ;{ }^{*} \mathrm{p}=0.03 ;{ }^{* * *} \mathrm{p}=0.02 ; \mathrm{MSS}$, microsatellite stable; MSI, microsatellite instability; TS, thymidylate synthase 
Table 3: Relationship between microsatellite instability status and TS expression, stratified by p53 expression.

\begin{tabular}{|c|c|c|c|c|}
\hline \multirow[t]{2}{*}{ p53 status } & \multirow[t]{2}{*}{ MSI status } & \multicolumn{2}{|c|}{ TS status } & \multirow[b]{2}{*}{ Total } \\
\hline & & Low & High & \\
\hline \multirow[t]{3}{*}{ All tumours } & MSS & 153 & 223 & 376 \\
\hline & MSI & 29 & 36 & 65 \\
\hline & Total & 182 & 259 & $44 I^{*}$ \\
\hline \multirow[t]{3}{*}{ p53 negative tumours } & MSS & 75 & 80 & 155 \\
\hline & MSI & 21 & 21 & 42 \\
\hline & Total & 96 & 101 & $197 * *$ \\
\hline \multirow[t]{3}{*}{ p53 positive tumours } & MSS & 78 & 143 & 221 \\
\hline & MSI & 8 & 15 & 23 \\
\hline & Total & 86 & 158 & $244^{* * * *}$ \\
\hline
\end{tabular}

$*_{p}=0.59 ; *_{p}=0.86 ; *^{* *} \mathrm{p}=1.0 ;$ MSS, microsatellite stable; MSI, microsatellite instability; TS, thymidylate synthase

between TP53 mutation and TS expression in a series of 36 CRCs and demonstrated that CRCs with p53 mutations affecting the zinc-binding domains had higher TS expression than those with mutation outside these domains [44]. Zinc domains are involved in direct DNA contact, protein stabilization, and structural activity, indicating that these mutations may have a severe impact on the transcriptional activity of p53.

Nine other studies have investigated the relationship between p53 and TS expression, based on immunohistochemistry, using p53 over-expression as a surrogate of TP53 mutation [8,45-52]. However, most have been based on small sample sizes (median 66, range 22[51]691[48]). Our results are consistent with four [44-46,50] of these studies, which also demonstrated a relationship between p53 and TS expression. Moreover, our study is the only one to assess this relationship stratified by MSI status. The relationship between p53 and TS was observed both in tumours with MSI and those with MSS, implying that aberrant mismatch repair is unlikely to impact on any mechanism relating p53 to TS expression. However, given the small number of samples with MSI, this cannot be entirely excluded.

As expected a highly significant inverse relationship between p53 status and MSI was observed. This relationship was independent of TS status, observed in both tumours expressing low and high TS levels ( $\mathrm{p} \leq 0.03$ ), and is consistent with the concept that most CRCs develop either along the chromosomal instability pathway associated with TP53 mutation and MSS tumours or the aberrant mismatch repair pathway associated with wild-type p53 and MSI tumours [53-56]. This association may also explain why tumours with MSI seem to have an improved prognosis compared to those with intact mismatch repair. However, we demonstrated no relationship between MSI and TS status. This finding was independent of p53 status. Whilst the precise mechanisms by which cells with MSI seem resistant to 5FU in vitro has been poorly defined, Ricciardiello et al. [57] have suggested that this may, in part, be due to TS over-expression TS. In their analysis of 192 CRCs the authors demonstrated an association between CRCs with MSI and high TS expression [57]. This observation was, however, contrary to an earlier study based on an analysis of 53 CRCs, which also observed no relationship between TS expression and the MSI phenotype [58]. Moreover, the study by Ricciardiello et al. [57] was based on only 24 CRCs with MSI and the rate of high TS expression in their study was at the lower end of that previously reported (21\%) [16] and may have biased findings. Our data, based on a sample size over two times larger, precludes at least a 16\% difference between MMR status and high TS expression at the 5\% threshold, with 90\% power.

Our results provide little evidence that TS expression plays a major role in defining chemoresistance in microsatellite unstable CRCs, but gives support to previous reports of an inverse relationship between MSI and p53 status. In addition, we demonstrated that TS expression is related to p53 status, and this relationship may in part account for the poorer prognosis and relative chemoresistance seen in these tumours.

\section{Conclusion}

Relationships exist between TS expression and p53 status, and MSI and p53 status in CRC that may account for the clinical phenotypes of these tumours. High TS expression 
is unlikely to play a major role in the clinical behaviour of CRCs characterised by MMR deficiency.

\section{Competing interests}

The author(s) declare that they have no competing interests.

\section{Authors' contributions}

RW and SP carried out the molecular and immunohistochemical studies. SP and RSH reviewed results and assigned tumour categories. RW participated in study design. SP and RSH conceived the study, performed the statistical analysis, and drafted the manuscript. All authors read and approved the final manuscript.

\section{Acknowledgements}

This work was supported by a grant form the Association for International Cancer Research and the UK Department of Health. Work in the laboratory of RSH is supported by grants from Cancer Research UK. We are grateful to Dr Wynne Aherne, Section of Cancer Therapeutics, Institute of Cancer Research, for generously providing anti-TS antibody.

\section{References}

I. Parkin DM, Pisani P, Ferlay J: Estimates of the worldwide incidence of eighteen major cancers in 1985. Int J Cancer 1993, 54:594-606.

2. Finlay IG, Pickford IR: Colorectal carcinoma. In Current medicine 4th edition. Edited by: Lawson DH. Edinburgh, Churchill Livingston; 1994:5I-64.

3. Cancer Research UK Large Bowel Cancer Factsheet (April 2005) 2005 [http://info.cancerresearchuk.org/images/publicationsp $\mathrm{dfs} /$ factsheet bowel 2005.pdf].

4. Vogelstein B, Fearon ER, Hamilton SR, Kern SE, Preisinger AC, Leppert M, Nakamura Y, White R, Smits AM, Bos JL: Genetic alterations during colorectal-tumor development. N Engl J Med 1988, 319:525-532.

5. Lynch HT, Smyrk TC, Watson P, Lanspa SJ, Lynch JF, Lynch PM, Cavalieri RJ, Boland CR: Genetics, natural history, tumor spectrum, and pathology of hereditary nonpolyposis colorectal cancer: an updated review. Gastroenterology 1993, 104:1535-1549.

6. Ilyas M, Straub J, Tomlinson IP, Bodmer WF: Genetic pathways in colorectal and other cancers. Eur / Cancer 1999, 35:335-35I.

7. Watanabe T, Wu TT, Catalano PJ, Ueki T, Satriano R, Haller DG, Benson ABIII, Hamilton SR: Molecular predictors of survival after adjuvant chemotherapy for colon cancer. $N$ Engl J Med 200I, 344: II 196-I206.

8. Edler D, Kressner U, Ragnhammar P, Johnston PG, Magnusson I, Glimelius B, Pahlman L, Lindmark G, Blomgren H: Immunohistochemically detected thymidylate synthase in colorectal cancer: an independent prognostic factor of survival. Clin Cancer Res 2000, 6:488-492.

9. Diep CB, Thorstensen L, Meling GI, Skovlund E, Rognum TO, Lothe RA: Genetic tumor markers with prognostic impact in Dukes' stages B and C colorectal cancer patients. J Clin Oncol 2003, 2 I:820-829.

10. Popat S, Hubner R, Houlston RS: Systematic review of microsatellite instability and colorectal cancer prognosis. J Clin Oncol 2005, 23:609-608.

II. Arnold CN, Goel A, Boland CR: Role of hMLHI promoter hypermethylation in drug resistance to 5 -fluorouracil in colorectal cancer cell lines. Int ] Cancer 2003, 106:66-73.

12. Carethers JM, Chauhan DP, Fink D, Nebel S, Bresalier RS, Howell SB, Boland CR: Mismatch repair proficiency and in vitro response to 5-fluorouracil. Gastroenterology 1999, I| 7:|23-131.

13. Johnston PG, Drake JC, Trepel J, Allegra CJ: Immunological quantitation of thymidylate synthase using the monoclonal antibody TS 106 in 5-fluorouracil-sensitive and -resistant human cancer cell lines. Cancer Res 1992, 52:4306-4312.
14. Santi DV, McHenry CS, Sommer H: Mechanism of interaction of thymidylate synthetase with 5-fluorodeoxyuridylate. Biochemistry 1974, 1 3:47|-48I.

15. Berger SH, Jenh CH, Johnson LF, Berger FG: Thymidylate synthase overproduction and gene amplification in fluorodeoxyuridine-resistant human cells. Mol Pharmacol 1985, 28:46 I-467.

16. Popat S, Matakidou A, Houlston RS: Thymidylate synthase expression and prognosis in colorectal cancer: a systematic review and meta-analysis. J Clin Oncol 2004, 22:529-536.

17. Petersen S, Thames HD, Nieder C, Petersen C, Baumann M: The results of colorectal cancer treatment by p53 status: treatment-specific overview. Dis Colon Rectum 200I, 44:322-333.

18. Russo A, Bazan V, lacopetta B, Kerr D, Soussi T, Gebbia N, TP: The TP53 Colorectal Cancer International Collaborative Study on the Prognostic and Predictive Significance of p53 Mutation: Influence of Tumor Site, Type of Mutation, and Adjuvant Treatment. J Clin Oncol 2005, 23:75I 8-7528.

19. McBride OW, Merry D, Givol D: The gene for human p53 cellular tumor antigen is located on chromosome 17 short arm (I7p | 3). Proc Natl Acad Sci U S A 1986, 83: I30-134.

20. Lane DP, Benchimol S: p53: oncogene or anti-oncogene? Genes Dev 1990, 4: I-8.

21. Rodrigues NR, Rowan A, Smith ME, Kerr IB, Bodmer WF, Gannon JV, Lane DP: p53 mutations in colorectal cancer. Proc Natl Acad Sci U S A 1990, 87:7555-7559.

22. Stretch JR, Gatter KC, Ralfkiaer E, Lane DP, Harris AL: Expression of mutant p53 in melanoma. Cancer Res 199I, 5I:5976-5979.

23. Varley JM, Brammar WJ, Lane DP, Swallow JE, Dolan C, Walker RA: Loss of chromosome 17p/3 sequences and mutation of p53 in human breast carcinomas. Oncogene 199I, 6:4I3-42I.

24. Bartek J, Bartkova J, Vojtesek B, Staskova Z, Lukas J, Rejthar A, Kovarik J, Midgley CA, Gannon JV, Lane DP: Aberrant expression of the $\mathrm{p} 53$ oncoprotein is a common feature of a wide spectrum of human malignancies. Oncogene 1991, 6:1699-1703.

25. Levine AJ, Momand J, Finlay CA: The p53 tumour suppressor gene. Nature 199I, 35 I:453-456

26. Loukola A, Eklin K, Laiho $P$, Salovaara R, Kristo $P$, Jarvinen $H$, Mecklin $J P$, Launonen V, Aaltonen LA: Microsatellite Marker Analysis in Screening for Hereditary Nonpolyposis Colorectal Cancer (HNPCC). Cancer Res 200I, 6 I:4545-4549.

27. Zhou XP, Hoang JM, Li YJ, Seruca R, Carneiro F, Sobrinho-Simoes M, Lothe RA, Gleeson CM, Russell SE, Muzeau F, Flejou JF, Hoang-Xuan $\mathrm{K}$, Lidereau R, Thomas G, Hamelin R: Determination of the replication error phenotype in human tumors without the requirement for matching normal DNA by analysis of mononucleotide repeat microsatellites. Genes Chromosomes Cancer 1998, 21:101-107.

28. Hsu SM, Raine L, Fanger $\mathrm{H}$ : The use of antiavidin antibody and avidin-biotin-peroxidase complex in immunoperoxidase technics. Am J Clin Pathol 198I, 75:816-82I.

29. Van der Wilt CL, Smid K, Aherne GW, Pinedo HM, Peters GJ: Evaluation of immunohistochemical staining and activity of thymidylate synthase in cell lines. Adv Exp Med Biol 1993, 338:605-608.

30. Munro AJ, Lain S, Lane DP: P53 abnormalities and outcomes in colorectal cancer: a systematic review. $\mathrm{Br}$ J Cancer 2005, 92:434-444

31. Finlay CA, Hinds PW, Tan TH, Eliyahu D, Oren M, Levine AJ: Activating mutations for transformation by $\mathrm{p} 53$ produce a gene product that forms an hsc70-p53 complex with an altered half-life. Mol Cell Biol I 988, 8:53I-539.

32. Chu E, Voeller D, Koeller DM, Drake JC, Takimoto CH, Maley GF, Maley F, Allegra CJ: Identification of an RNA binding site for human thymidylate synthase. Proc Natl Acad Sci U S A 1993, 90:517-521.

33. Chu E, Koeller DM, Casey JL, Drake JC, Chabner BA, Elwood PC, Zinn S, Allegra CJ: Autoregulation of human thymidylate synthase messenger RNA translation by thymidylate synthase. Proc Natl Acad Sci U S A 1991, 88:8977-8981.

34. Lin X, Parsels LA, Voeller DM, Allegra CJ, Maley GF, Maley F, Chu E: Characterization of a cis-acting regulatory element in the protein coding region of thymidylate synthase mRNA. Nucleic Acids Res 2000, 28: I38I-1389.

35. Chu E, Cogliati T, Copur SM, Borre A, Voeller DM, Allegra C], Segal $S$ : Identification of in vivo target RNA sequences bound by thymidylate synthase. Nucleic Acids Res 1996, 24:3222-3228. 
36. Lee $Y$, Chen $Y$, Chang LS, Johnson LF: Inhibition of mouse thymidylate synthase promoter activity by the wild-type p53 tumor suppressor protein. Exp Cell Res 1997, 234:270-276.

37. Chu E, Copur SM, Ju J, Chen TM, Khleif S, Voeller DM, Mizunuma N, Patel M, Maley GF, Maley F, Allegra CJ: Thymidylate synthase protein and p53 mRNA form an in vivo ribonucleoprotein complex. Mol Cell Biol 1999, 19:1582-I594.

38. Longley D, Latif T, Boyer J, Allen W, Maxwell P, Johnston P: The interaction of thymidylate synthase expression with p53-regulated signaling pathways in tumor cells. Seminars in Oncology 2003, 30:3-9.

39. Kastanos EK, Zajac-Kaye M, Dennis PA, Allegra C): Downregulation of $\mathrm{p} 2 \mathrm{I} / \mathrm{WAFI}$ expression by thymidylate synthase. Biochem Biophys Res Commun 200I, 285: 195-200.

40. Kim E, Deppert W: Transcriptional activities of mutant p53: when mutations are more than a loss. J Cell Biochem 2004, 93:878-886.

4I. Miller CW, Chumakov A, Said J, Chen DL, Aslo A, Koeffler HP. Mutant $\mathrm{p} 53$ proteins have diverse intracellular abilities to oligomerize and activate transcription. Oncogene 1993, 8: $18 \mid 5-1824$.

42. Park DJ, Nakamura H, Chumakov AM, Said JW, Miller CW, Chen DL, Koeffler HP: Transactivational and DNA binding abilities of endogenous p53 in p53 mutant cell lines. Oncogene 1994, 9:1899-1906.

43. Lenz HJ, Hayashi K, Salonga D, Danenberg KD, Danenberg PV, Metzger R, Banerjee D, Bertino JR, Groshen S, Leichman LP, Leichman CG: $\mathbf{p} 53$ point mutations and thymidylate synthase messenger RNA levels in disseminated colorectal cancer: an analysis of response and survival. Clin Cancer Res 1998, 4: $1243-1250$

44. Lenz HJ, Danenberg KD, Leichman CG, Florentine B, Johnston PG Groshen S, Zhou L, Xiong YP, Danenberg PV, Leichman LP: p53 and thymidylate synthase expression in untreated stage II colon cancer: associations with recurrence, survival, and site. Clin Cancer Res 1998, 4: I 227-1234.

45. Paradiso A, Simone G, Petroni S, Leone B, Vallejo C, Lacava J, Romero A, Machiavelli M, De Lena M, Allegra CJ, Johnston PG: Thymidilate synthase and $\mathrm{p} 53$ primary tumour expression as predictive factors for advanced colorectal cancer patients. $\mathrm{Br} J$ Cancer 2000, 82:560-567.

46. Etienne MC, Chazal M, Laurent-Puig P, Magne N, Rosty C, Formento $J$, Francoual M, Formento P, Renee N, Chamorey E, Bourgeon A, Seitz JF, Delpero JR, Letoublon C, Pezet D, Milano G: Prognostic value of tumoral thymidylate synthase and $p 53$ in metastatic colorectal cancer patients receiving fluorouracil-based chemotherapy: phenotypic and genotypic analyses. J Clin Oncol 2002, 20:2832-2843.

47. Allegra C], Paik S, Colangelo LH, Parr AL, Kirsch I, Kim G, Klein P, Johnston PG, Wolmark N, Wieand HS: Prognostic value of thymidylate synthase, Ki-67, and p53 in patients with Dukes' B and $C$ colon cancer: a National Cancer Institute-National Surgical Adjuvant Breast and Bowel Project collaborative study. J Clin Oncol 2003, 2 1:24I-250.

48. Allegra CJ, Parr AL, Wold LE, Mahoney MR, Sargent DJ, Johnston P, Klein P, Behan K, O'Connell MJ, Levitt R, Kugler JW, Tria TM, Goldberg RM: Investigation of the prognostic and predictive value of thymidylate synthase, $\mathrm{p} 53$, and $\mathrm{Ki}-67$ in patients with locally advanced colon cancer. J Clin Oncol 2002, 20: I735- I743.

49. Berglund A, Edler D, Molin D, Nordlinder H, Graf W, Glimelius B: Thymidylate synthase and $\mathrm{p} 53$ expression in primary tumor do not predict chemotherapy outcome in metastatic colorectal carcinoma. Anticancer Res 2002, 22:3653-3659.

50. Aschele C, Debernardis D, Tunesi G, Maley F, Sobrero A: Thymidylate Synthase Protein Expression in Primary Colorecta Cancer Compared with the Corresponding Distant Metastases and Relationship with the Clinical Response to 5-Fluorouracil. Clin Cancer Res 2000, 6:4797-4802.

5I. Edler D, Hallstrom M, Johnston PG, Magnusson I, Ragnhammar P, Blomgren $\mathrm{H}$ : Thymidylate synthase expression: an independent prognostic factor for local recurrence, distant metastasis, disease-free and overall survival in rectal cancer. Clin Cancer Res 2000, 6: I378-1384.

52. Perucho M, Peinado MA, lonov Y, Casares S, Malkhosyan S, Stanbridge E: Defects in replication fidelity of simple repeated sequences reveal a new mutator mechanism for oncogenesis. Cold Spring Harb Symp Quant Biol 1994, 59:339-348.

53. Perucho M: Cancer of the microsatellite mutator phenotype. Biol Chem 1996, 377:675-684.

54. Jones AM, Douglas EJ, Halford SE, Fiegler H, Gorman PA, Roylance RR, Carter NP, Tomlinson IP: Array-CGH analysis of microsatellite-stable, near-diploid bowel cancers and comparison with other types of colorectal carcinoma. Oncogene 2005, 24:118-129.

55. lonov $Y$, Peinado MA, Malkhosyan S, Shibata D, Perucho M: Ubiquitous somatic mutations in simple repeated sequences reveal a new mechanism for colonic carcinogenesis. Nature 1993 , 363:558-561.

56. Ricciardiello L, Ceccarelli C, Angiolini G, Pariali M, Chieco P, Paterini P, Biasco G, Martinelli GN, Roda E, Bazzoli F: High Thymidylate Synthase Expression in Colorectal Cancer with Microsatellite Instability: Implications for Chemotherapeutic Strategies. Clin Cancer Res 2005, I I:4234-4240.

57. Merkelbach-Bruse S, Hans V, Mathiak M, Sanguedolce R, Alessandro R, Ruschoff J, Buttner R, Houshdaran F, Gullotti L: Associations between polymorphisms in the thymidylate synthase gene, the expression of thymidylate synthase mRNA and the microsatellite instability phenotype of colorectal cancer. Oncol Rep 2004, I I:839-843.

\section{Pre-publication history}

The pre-publication history for this paper can be accessed here:

\section{http://www.biomedcentral.com/1471-2407/6/150/pre} pub
Publish with Bio Med Central and every scientist can read your work free of charge

"BioMed Central will be the most significant development for disseminating the results of biomedical research in our lifetime. "

Sir Paul Nurse, Cancer Research UK

Your research papers will be:

- available free of charge to the entire biomedical community

- peer reviewed and published immediately upon acceptance

- cited in PubMed and archived on PubMed Central

- yours - you keep the copyright 